\title{
Mildly Symptomatic Chronic Mitral Regurgitation. Analysis of Left Ventricular Systolic Function and Mitral Regurgitant Fraction Under Pharmacological Influence. Echocardiographic Study
}

\author{
Ivan Romero Rivera, Valdir Ambrósio Moisés, Antonio Carlos Carvalho, Angelo Amato V. de Paola
}

São Paulo, SP - Brazil

\begin{abstract}
Objective: To study echocardiographic parameters of left ventricular systolic function and valvar regurgitation under pharmacological influence in mildly symptomatic patients with chronic mitral regurgitation (MR).

Methods: We carried out a double-blind placebo controlled study in 12 patients with MR, mean aged 12.5 years old, who were randomized in 4 phases: A) digoxin; B) enalapril; C) digoxin + enalapril; D) placebo. The medication was administered for 30 days in each phase, and the following variables were analyzed: shortening and ejection fractions, wall stress index of left ventricle, left ventricular meridional end-systolic wall stress, Doppler-derived mean rate of left ventricular pressure rise (mean $d P / d t$ ), stroke volume and MR jet area. The clinical variables analysed were heart rate and systemic arterial pressure.
\end{abstract}

Results: No significant variation was observed in the clinical variables analysed. The shortening and ejection fraction, the mean $\mathrm{dP} / \mathrm{dt}$ and stroke volume significantly increased and the wall stress index of left ventricle, the meridional left ventricular end systolic wall stress and the mitral regurgitation jet area decreased in the phases with medication as compared with that in the placebo phase.

Conclusion: The parameters of left ventricular systolic function improved significantly and the degree of MR decreased with the isolated administration of digoxin or enalapril in mildly symptomatic patients with chronic MR. The combination of the drugs, however, did not show better results.

Keywords: echocardiography, left ventricular function, mitral regurgitation

Escola Paulista de Medicina - UNIFESP

Mailing address: Ivan Romero Rivera - Av. Mario de Gusmão, 1281/404 - 57035000 - Maceió, AL, Brazil - E-mail: irrivera@uol.com.br

English version by Stela Maris C. e Gandour
Mitral regurgitation with a rheumatic etiology is a frequent problem in developing countries ${ }^{1}$. Although the clinical treatment has been well established for symptomatic patients or patients with left ventricular dysfunction ${ }^{2}$, the same has not happened with asymptomatic or mildly symptomatic patients with mitral regurgitation with hemodynamic repercussion, who have been empirically medicated with digitalis or vasodilators, or both.

Although these drugs have confirmed usefulness in situations in which heart failure becomes evident ${ }^{3,4}$, their efficacy in individuals with preserved ventricular function, and, therefore, asymptomatic or mildly symptomatic, has not yet been well defined.

No middle- or long-term studies exist analyzing the response of ventricular function parameters to the pharmacological effects of digitalis or vasodilators, or both, in children and adolescents with chronic mitral regurgitation and preserved ventricular function. The few data available are related to studies in healthy adults ${ }^{5}$, in patients with mitral regurgitation secondary to cardiomyopathy ${ }^{3,4}$, and in adults with mildly symptomatic mitral regurgitation of different etiologies, both with a single dose ${ }^{6,7}$ or with prolonged medication ${ }^{8-13}$.

The major aim of this study was to analyze the behavior of some ventricular function parameters and the degree of valvular regurgitation under the prolonged use of digitalis and enalapril in mildly symptomatic children and adolescents with chronic mitral regurgitation with a rheumatic etiology.

\section{Methods}

The study comprised mildly symptomatic patients (NYHA FC I-II) with chronic mitral valvular regurgitation clinically detected or detected on echocardiography. The hemodynamic repercussion, defined as the dilation of the cardiac chambers due to valvular regurgitation, was considered an inclusion criterion. 
The exclusion criteria were: presence of rheumatic activity in the 6 months preceding the beginning of the study or laboratory tests compatible with the acute phase of the disease; myocardial disease of any etiology; systemic or congenital disease, or both; pulmonary or systemic arterial hypertension, or both; multivalvular disease or associated mitral stenosis. The exclusion criteria during the study were as follows: worsening of the patient's functional class; symptomatic arterial hypotension; acute rheumatic fever clinically detected or detected through laboratory tests, or both, or alterations in the laboratory tests due to the use of medication, or both.

Penicillin benzathine was maintained in all patients. After 15 days of no oral medication, the patients underwent clinical examination, 12-lead electrocardiography, chest Xray, echocardiography and cardiopulmonary exercise testing. They were then randomized into 4 phases: A: digoxin + placebo; B: enalapril + placebo; C: digoxin + enalapril; and D: placebo + placebo. Because it was a double-blind study, the medication was always combined with a placebo to avoid the recognition of phase $C$. Randomization was performed in a way that each phase always had 3 patients, and, at the end of the study, the 12 patients had passed the 4 phases (fig. 1).

The medication was administered for 30 days in each phase, as follows: a) digoxin -if weight $<25 \mathrm{~kg}=10 \mathrm{mcg} / \mathrm{kg} /$ day, if weight $>25 \mathrm{~kg}=0.25 \mathrm{mg} /$ day; b) enalapril maleate - if weight $<25 \mathrm{~kg}=0.2 \mathrm{mg} / \mathrm{kg} /$ day, if weight $>25 \mathrm{~kg}=5 \mathrm{mg} /$ day. This was a prospective double-blind study, the drugs were used for 30 days, and the washout period lasted 10 days. The mean duration of the study was 150 days and the patients were clinically assessed every 10 days, and assessed with laboratory tests (ESR, ASO, PCR, and serum creatinine, sodium, and potassium) every 15 days.

An echocardiographic study was performed at the beginning and end of each phase. After a 15-minute rest, the patient's heart rate and blood pressure were measured, and, immediately afterwards, the examination began. Based on data of systolic and diastolic blood pressure, the mean blood pressure was calculated with the following formula: $\mathrm{MBP}=[(\mathrm{SBP}-\mathrm{DBP}) / 3]+\mathrm{DBP}$.

The echocardiographic images were obtained with the Ultramark 7 device (Advanced Technology Laboratories, USA) and a 2.5-mHz transducer, equipped with pulsed Doppler (PD), continuous Doppler (CD), and color flow map- ping. The longitudinal and transverse parasternal views and the apical 2-chamber and 4-chamber views were used. Heart rate was monitored during the study with an electrocardiographic lead. On the first examination, the exact position of the transducer to be used in the subsequent examinations was determined, as was the size of the volume sample for the examinations with pulsed Doppler $(1 \mathrm{~mm})$. On color flow mapping, the Nyquist limit of $61 \mathrm{~cm} / \mathrm{s}$ was established for all patients, and the gain level to be used for each patient in the subsequent examinations was defined as that situated immediately below the "static noise" level in the image of the first examination. The examinations were recorded on videotapes for further analysis and all measurements obtained were evaluated in 5 consecutive heart beats during the expiratory phase of breathing by 2 observers; a mean was used for the calculation. After a complete 2-dimensional examination with the patient in the left lateral decubitus position, the following parameters were assessed on M mode: left ventricular diastolic and systolic diameters, and diastolic and systolic thickness of the interventricular septum and of the posterior wall as recommended by the American Society of Echocardiography ${ }^{14}$.

For determining the ejection fraction, the left ventricular end-diastolic and end-systolic volumes were calculated according to the following formula: $\mathrm{Vol}=[7 /(2.4+\mathrm{D})] \mathrm{D}^{315}$, in which $\mathrm{D}$ is the left ventricular diameter in $\mathrm{cm}$, the result being expressed in $\mathrm{cm}^{3}$. The stroke volume was calculated according to the formula: SV = VTI x CSA, in which VTI is the velocity-time integral of the aortic flow obtained with pulsed Doppler immediately below the aortic valve in the apical 4-chamber view, and CSA is the cross-sectional area calculated at the same place in the longitudinal parasternal view ${ }^{16}$. The result was expressed in $\mathrm{cm}^{3}$. Valvular regurgitation was quantified by color flow mapping in the longitudinal, transverse, and apical 2- and 4-chamber views with the mean of the results being used for calculating the regurgitant fraction $(\mathrm{RF} \%=\text { regurgitant jet area/left atrial area })^{17}$.

Left ventricular systolic function was quantified with the shortening fraction (DD $\%=[(\mathrm{DD}-\mathrm{SD}) / \mathrm{DD}] \times 100)^{18}$ and the ejection fraction $(\mathrm{EF} \%=[(\mathrm{DVol}-\mathrm{SVol}) / \mathrm{DVol}] \times 100){ }^{19}$. Left ventricular end-systolic wall stress $($ Wss $=S B P \times R / h)$ expressed in $\mathrm{mm} \mathrm{Hg}$ was calculated, as was left ventricular end-systolic meridional wall stress ${ }^{20,21}(\mathrm{ESWS}=(\mathrm{SBP} \times \mathrm{D} \mathrm{x}$ $1.35) /(\mathrm{h})(1+\mathrm{h} / \mathrm{D})(4)$ expressed in $\mathrm{g} / \mathrm{cm}^{2}$. In these formulas,

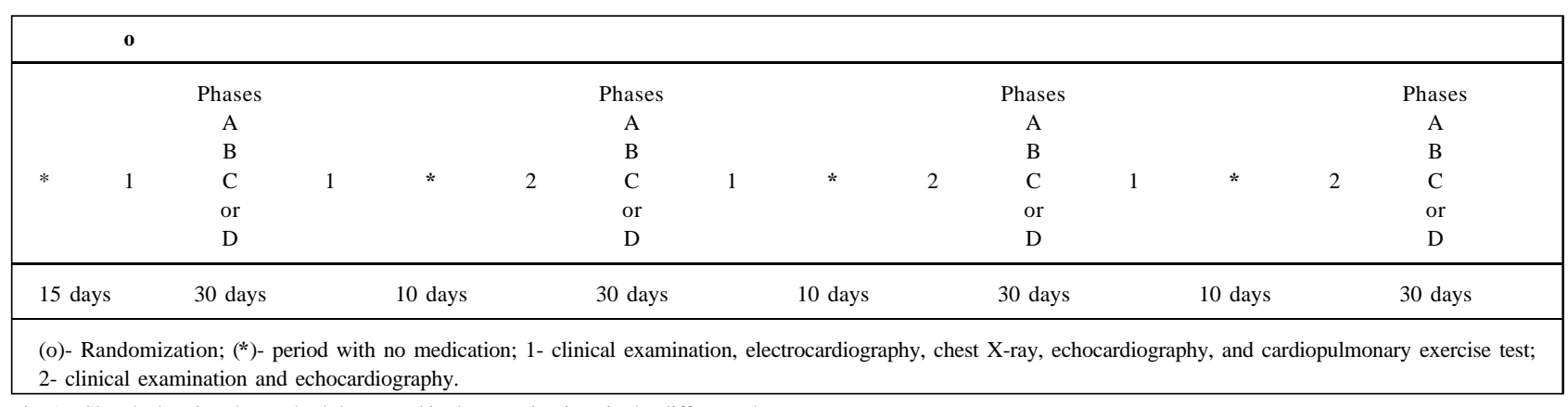

Fig. 1 - Sketch showing the methodology used in the examinations in the different phases 
SBP is systolic systemic blood pressure, $\mathrm{D}$ is the left ventricular systolic diameter, $\mathrm{h}$ is the systolic wall thickness, 1.35 is the converting factor from $\mathrm{mm} \mathrm{Hg}$ to $\mathrm{g} / \mathrm{cm}^{2}$, and $\mathrm{R}$ is the left ventricular systolic radius $(\mathrm{D} / 2)$.

The incremental rate of left ventricular pressure in respect to time, or mean left ventricular $\mathrm{dP} / \mathrm{dt}$, was also calculated ${ }^{22}$ based on a curve of mitral regurgitation velocity obtained with cardiac output oriented by color flow mapping in apical 4-chamber view. The time necessary for a variation of $32 \mathrm{~mm} \mathrm{Hg}$ in left ventricular pressure (velocity of $1 \mathrm{~m} / \mathrm{seg}$ to $4 \mathrm{~m} / \mathrm{seg}$ ) was calculated in milliseconds, and this time was used as the denominator of the relation $\mathrm{dP} / \mathrm{dt}=$ $(32 \mathrm{~mm} \mathrm{Hg} / \mathrm{t}) \times 1000$. With this objective, the regurgitation curves with the best definition of the borders were selected, and a difference of up to $20 \mathrm{~mm} \mathrm{Hg}$ between the systolic peak of the curve and the patient's systolic blood pressure was accepted as valid.

All patients underwent a complete echocardiographic examination at the beginning of the study, which was used as a model in subsequent examinations. If the measurements in the different subsequent examinations had a variation greater than $10 \%$, new measurements were performed to confirm the findings, and, therefore, to avoid intrinsic variations depending on the position of the transducer. To test the inter- and intraobserver variability, 10 examinations were randomly chosen, and the results obtained by the 2 observers participating in the study were compared.

The Wilcoxon test was used for analyzing ventricular function, stroke volume, and regurgitant fraction. The paired $t$ test was used for analyzing the left ventricular systolic and diastolic diameters, heart rate, and blood pressure. The interphase variability was studied by using $\Delta \%=$ [(Post-Pre)/Pre] x 100, and the results were analyzed with the Friedman test comparing $\Delta \% \mathrm{~A} x \Delta \% \mathrm{~B} x \Delta \% \mathrm{C} x \Delta \% \mathrm{D}$; the results with significant differences were compared with the multiple comparisons procedure. The cardiothoracic ratio was analyzed with the Friedman test. The statistical significance level of $p \leq 0.05$ was adopted. The inter- and in- traobserver variabilities were studied with the correlation coefficient using linear regression analysis.

\section{Results}

We prospectively studied 12 patients ( 9 females) with a mean age of $12.5 \pm 2.4$ years (6-15 years) and body surface between 0.79 and $1.63 \mathrm{~m}^{2}$, who had chronic mitral regurgitation with a rheumatic etiology (outpatient care unit followup $\geq 6$ months) with hemodynamic repercussion. Nine patients were in NYHA functional class I, and 3 patients were in NYHA functional class II. All patients were receiving penicillin benzathine, and the 3 in functional class II were taking $10 \mathrm{mcg} / \mathrm{kg} / \mathrm{day}$ of digoxin.

At the beginning of the study, the mean diastolic diameter on echocardiography was $58.6 \mathrm{~mm}$ ( 51 to $73 \mathrm{~mm}$ ) corresponding to an increase of 12 to $55 \%$ in the superior limit of the data standardized for body surface by the American Society of Echocardiography ${ }^{23}$; the mean systolic diameter was $36.6 \mathrm{~mm}$ ( 31 to $47 \mathrm{~mm}$ ); the mean $\Delta \mathrm{D} \%$ was $38.08 \%$ ( 34 to $42 \%$ ); and the mean ejection fraction was $67.25 \%$ (62 to $72 \%$ ). All patients had sinus rhythm on the electrocardiogram and a cardiothoracic ratio between 0.35 and 0.59 on chest X-ray (tab. I).

Clinically, no alteration in functional class existed, no patient was excluded from the study and all patients passed though the 4 phases. No change in the electrocardiographic findings was observed when analyzing the QRS complex, the ventricular repolarization or the QT interval. The chest $\mathrm{X}$-ray showed no evident alteration in the pulmonary flow pattern, and the cardiothoracic ratio had no significant variation. The mean values in the different phases were as follows: Pre $=0.47 ; \mathrm{A}=0.46 ; \mathrm{B}=0.46 ; \mathrm{C}=0.47$; and $\mathrm{D}=0.47$.

Heart rate, systolic, diastolic, and mean blood pressures, and left ventricular diastolic diameter showed no significant variation when the pre- and postdata were compared in the different phases (tab. II).

The end-systolic diameter showed a significant reduction in the phases A, B, and C, and no significant varia-

Table I - Characteristics of the patients in baseline conditions distributed according to age, functional class, weight, body surface, blood pressure, and echocardiographic data

\begin{tabular}{|c|c|c|c|c|c|c|c|c|c|}
\hline \multirow[t]{2}{*}{$\mathrm{Pt}$} & \multirow[t]{2}{*}{ Age } & \multirow[t]{2}{*}{$\mathrm{FC}$} & \multirow[t]{2}{*}{ weight } & \multirow[t]{2}{*}{ BS } & \multirow[t]{2}{*}{$\mathrm{BP}$} & \multirow[t]{2}{*}{ ECG } & \multirow[t]{2}{*}{ CTR } & \multicolumn{2}{|c|}{ Echocardiogram } \\
\hline & & & & & & & & DD & $\mathrm{SD}$ \\
\hline 01 & 10 & I & 41 & 1.33 & $120 \times 70$ & $\mathrm{Sin} / \mathrm{LAO}$ & 0.45 & 55 & 32 \\
\hline 02 & 13 & I & 43 & 1.43 & $110 \times 70$ & $\mathrm{Sin} / \mathrm{LAO}$ & 0.46 & 73 & 47 \\
\hline 03 & 14 & I & 51 & 1.55 & $120 \times 80$ & $\mathrm{Sin} / \mathrm{Nl}$ & 0.44 & 57 & 34 \\
\hline 04 & 12 & I & 33 & 1.15 & $104 \times 74$ & $\mathrm{Sin} / \mathrm{LAO}$ & 0.45 & 51 & 31 \\
\hline 05 & 14 & I & 40 & 1.33 & $130 \times 70$ & $\mathrm{Sin} / \mathrm{Nl}$ & 0.48 & 56 & 35 \\
\hline 07 & 15 & I & 49 & 1.46 & $130 \times 80$ & $\mathrm{Sin} / \mathrm{LAO}$ & 0.45 & 55 & 37 \\
\hline 08 & 13 & II & 50 & 1.42 & $120 \times 80$ & $\mathrm{Sin} / \mathrm{LAO}$ & 0.55 & 65 & 39 \\
\hline 09 & 6 & I & 20 & 0.79 & $90 \times 60$ & $\mathrm{Sin} / \mathrm{LAO}$ & 0.52 & 59 & 35 \\
\hline 10 & 14 & I & 55 & 1.55 & $114 \times 80$ & $\mathrm{Sin} / \mathrm{LAO}$ & 0.44 & 57 & 36 \\
\hline 11 & 13 & I & 62 & 1.63 & $106 \times 70$ & $\mathrm{Sin} / \mathrm{LAO}$ & 0.35 & 56 & 35 \\
\hline 12 & 15 & II & 49 & 1.52 & $114 \times 76$ & $\mathrm{Sin} / \mathrm{LAO}$ & 0.45 & 64 & 42 \\
\hline
\end{tabular}

Pt - patient; FC - functional class; BS - body surface; BP - systemic blood pressure; ECG - electrocardiogram; Sin - sinus rhythm; LAO - left atrial overload; Nl normal; CTR - cardiothoracic ratio; DD - diastolic diameter; SD - systolic diameter. 


\begin{tabular}{|c|c|c|c|c|c|c|c|c|}
\hline & \multicolumn{2}{|c|}{ A } & \multicolumn{2}{|c|}{$\mathrm{B}$} & \multicolumn{2}{|c|}{$\mathrm{C}$} & \multicolumn{2}{|c|}{$\mathrm{D}$} \\
\hline & Pre & Post & Pre & Post & Pre & Post & Pre & Post \\
\hline HR & 81.7 & 81.6 & 86.1 & 82.9 & 83.8 & 81.5 & 85.1 & 85.1 \\
\hline SBP & 115.4 & 115.8 & 113.3 & 112.1 & 117.1 & 112.9 & 116.2 & 114.6 \\
\hline DBP & 74.2 & 76.7 & 73.3 & 72.9 & 79.2 & 73.8 & 77.9 & 76.7 \\
\hline MBP & 87.9 & 89.7 & 86.7 & 86 & 91.7 & 86.7 & 90.8 & 89.1 \\
\hline LVDD & 59.3 & 58.8 & 59.1 & 59.3 & 59.3 & 58.9 & 59 & 58.8 \\
\hline LVSD & 37 & $35.9^{* *}$ & 37.2 & $36.3^{* *}$ & 37.8 & $35.8^{* *}$ & 37.3 & 37.4 \\
\hline $\mathrm{DD} \%$ & 37.5 & 38.9 & 37 & $38.8^{* *}$ & 36.3 & $39.2^{* *}$ & 36.9 & 36.3 \\
\hline $\mathrm{EF} \%$ & 66.3 & $68.7^{*}$ & 66 & $68.3 * *$ & 65.3 & $69 * *$ & 65.9 & 65.3 \\
\hline ESWS & 86 & $76.3 * *$ & 86.7 & $78.5^{* *}$ & 91.8 & $73.3^{* *}$ & 86.4 & 91.3 \\
\hline Wss & 170.5 & $154.2 * *$ & 170.9 & $157.5 * *$ & 180.1 & $149.6^{* *}$ & 170.6 & 178.6 \\
\hline $\mathrm{dP} / \mathrm{dt}$ & 1180.6 & $1592.6 * *$ & 998 & $1157.5^{* *}$ & 1042.4 & $1409 * *$ & 1203.5 & 1179 \\
\hline $\mathrm{RF}$ & 27 & $24.9^{*}$ & 28.3 & 25.2 & 25.3 & 23 & 25.8 & 25.3 \\
\hline RJA & 6.4 & $5.6^{*}$ & 6.7 & 6.1 & 6.1 & 5.6 & 6.1 & 6.1 \\
\hline SV & 45.8 & $49.1^{*}$ & 45.8 & 47.6 & 45.7 & 47.8 & 48.3 & 46 \\
\hline $\begin{array}{l}\text { HR- hea } \\
\text { diameter } \\
\text { ventricu } \\
\text { time in }\end{array}$ & $\mathrm{t} / \mathrm{min}$; & $\begin{array}{l}\text { ic blood } \\
\text { ystolic di } \\
\text { stress in }\end{array}$ & DBP- & $\begin{array}{l}\text { od pressu } \\
\text { ntricular s } \\
\text { end-systo }\end{array}$ & mea & $\begin{array}{l}\text { Ire in } 1 \\
\text { - left } v \\
\text { dt- incr }\end{array}$ & $\begin{array}{l}\text { VDD- } \\
\text { ejection }\end{array}$ & $\begin{array}{l}\text { ar dias } \\
\text { ESWS- } \\
\text { a respe }\end{array}$ \\
\hline
\end{tabular}

tion in phase $\mathrm{D}(\mathrm{A}: \mathrm{p}=0.01 ; \mathrm{B}: \mathrm{p}=0.005 ; \mathrm{C}: \mathrm{p}=0.0004 ; \mathrm{D}$ : $\mathrm{p}=0.7)$. The multiple comparisons test showed that phase $C$ was the most different from the placebo phase, ie, $C>D$. The shortening fraction $(\Delta \mathrm{D} \%)$ had a significant increase in phases $\mathrm{B}$ and $\mathrm{C}$, and the ejection fraction (EF\%) in phases $\mathrm{A}, \mathrm{B}$, and $\mathrm{C}$, with no significant variation in phase $\mathrm{D}(\mathrm{A}$ : $\mathrm{p}=0.1$ and $\mathrm{p}=0.04 ; \mathrm{B}: \mathrm{p}=0.002$ and $\mathrm{p}=0.002 ; \mathrm{C}: \mathrm{p}=0.001$ and $\mathrm{p}=0.001 ; \mathrm{D}: \mathrm{p}=0.55$ and $\mathrm{p}=0.64$, respectively). The multiple comparisons test showed that phases $\mathrm{B}$ and $\mathrm{C}$ were the most different from the placebo phase, ie, $\mathrm{B}$ and $\mathrm{C}>\mathrm{D}$. The mean $\mathrm{dP} / \mathrm{dt}$ showed a significant increase in phases $\mathrm{A}, \mathrm{B}$, and $C$, with a mild reduction in phase $D(A: p=0.002$; : $\mathrm{p}=0.01 ; \mathrm{C}: \mathrm{p}=0.001 ; \mathrm{D}: \mathrm{p}=0.8)$. The multiple comparisons test showed that phases $\mathrm{A}$ and $\mathrm{C}$ were the most different from the placebo phase, ie, A and C > D. Both left ventricular endsystolic meridional wall stress (ESWS) and left ventricular end-systolic wall stress (Wss) showed significant reduction in phases $\mathrm{A}, \mathrm{B}$, and $\mathrm{C}$, and a mild increase in phase $\mathrm{D}(\mathrm{A}$ : $\mathrm{p}=0.007$ and $\mathrm{p}=0.007 ; \mathrm{B}: \mathrm{p}=0.003$ and $\mathrm{p}=0.005 ; \mathrm{C}: \mathrm{p}=0.009$ and $\mathrm{p}=0.01 ; \mathrm{D}: \mathrm{p}=0.3$ and $\mathrm{p}=0.3$, respectively). The stroke volume showed an increase in phases $\mathrm{A}, \mathrm{B}$, and $\mathrm{C}$, and a reduction in phase $D$; this increase, however, was only significant in phase $\mathrm{A}(\mathrm{A}: \mathrm{p}=0.03 ; \mathrm{B}: \mathrm{p}=0.2 ; \mathrm{C}: \mathrm{p}=0.4 ; \mathrm{D}: \mathrm{p}=0.3)$. Both the regurgitant fraction and the regurgitant jet area showed reductions in phases $\mathrm{A}, \mathrm{B}$, and $\mathrm{C}$, and no variation in phase $D$. This reduction, however, was only significant in phase $A(A: p=0.03$ and $0.04 ; B: p=0.07$ and $0.07 ; C: p=0.1$ and $0.2 ; \mathrm{D}: \mathrm{p}=0.8$ and 0.9 , respectively). The mean values of each parameter studied distributed in the different phases of the study are shown in table II.

Nine patients underwent the cardiopulmonary exercise test. Of the 12 patients studied, 2 did not undergo that test due to technical difficulties as follows: the first patient could not pedal due to lack of adaptation, and the second patient was short-statured, and, therefore, could not undergo the test. The third patient (patient 11) was excluded from the study because she did not undergo phase C. Eight patients were in functional class I in regard to oxygen consumption; 1 patient had data compatible with functional class III in the postplacebo phase. This phase had the lowest levels of maximum $\mathrm{VO}_{2}$; however, a significant difference between the prestudy data and those after phases $\mathrm{A}$, $\mathrm{B}$, or $\mathrm{C}$ did not exist. Maximum $\mathrm{VO}_{2}$ values in the different groups were as follows: $33 \pm 8.4(20-46.6)$ in the prestudy examination; $32.5 \pm 5.5(27.4-41.3)$ in phase $\mathrm{A} ; 31 \pm 6.4(24.6-$ 43.6) in phase $\mathrm{B} ; 34.8 \pm 10.8(19.3-55.7)$ in phase $\mathrm{C}$; and $25.4 \pm 7.6(10.3-36.2)$ in phase $\mathrm{D}$. The anaerobic threshold values were as follows: $25 \pm 5.1(16.3-33.6)$ in the prestudy examination; $25.7 \pm 6.2(15.9-33.3)$ in phase $\mathrm{A} ; 22.5 \pm 6.1$ (16.1 $-36.8)$ in phase $B ; 25.3 \pm 4.7(16.3-32.6)$ in phase $C$; and $18.7 \pm 5.2(7.9-25.9)$ in phase D.

The inter- and intraobserver correlation coefficients of the linear regression analysis were, respectively, 0.98 and 0.98 for left ventricular diastolic diameter; 0.99 and 0.97 for left ventricular systolic diameter; 0.99 and 0.99 for left atrial area; 0.98 and 0.97 for the regurgitant jet area; 0.95 and 0.98 for the aortic root measurement; 0.99 and 0.99 for the integral of time and velocity of the aortic flow; 0.92 and 0.94 for the $\mathrm{dt}$ measurement; and 0.94 and 0.98 for the $h$ measurement.

\section{Discussion}

Several indices have been proposed to assess left ventricular systolic function in patients with chronic mitral regurgitation with the purpose of analyzing the contractile function closely related to other factors, such as preload, afterload, and heart rate.

No previous study exists analyzing the behavior of the echocardiographic parameters of left ventricular systolic function under pharmacological intervention with digitalis and enalapril in asymptomatic children and adolescents with mitral regurgitation and hemodynamic repercussion with preserved left ventricular systolic function. 
Chronic mitral regurgitation causes volume overload in left chambers with a consequent increase in the preload conditions, which favors their performance through the Frank-Starling mechanism. Because part of the stroke volume is ejected to a low-pressure and high-compliance chamber, such as the left atrium, afterload in this situation is low or normal, being increased only in later periods of the disease evolution, when, despite these favorable conditions, the left ventricle has difficulty in ejecting its volume due to the systolic dysfunction. At this moment, heart failure becomes manifest with appearance of the symptoms due to low output and pulmonary congestion.

Several studies were carried out with patients with heart failure and mitral regurgitation, aiming at analyzing the clinical improvement of patients, ie, an improvement in functional class or a reduction in mortality at the long run, or both $^{3,4,24}$. Although repercussion in functional class is very important in the clinical follow-up, by definition it is unfeasible in asymptomatic patients.

In the present study, the behavior of some echocardiographic parameters of ventricular function under inotropic and vasodilating pharmacological action was analyzed in mildly symptomatic patients with chronic mitral regurgitation and normal ejection fraction at the beginning of the protocol.

The clinical data showed no significant variation in heart rate or blood pressure during the study. Because left ventricular diastolic diameter showed no significant variation in the different phases, preload was considered stable during the study. Although some studies have shown a reduction in diastolic diameter after the use of some vasodilators ${ }^{7,11,13}$, no changes in these parameters were observed in adults with cardiomyopathy receiving captopril and placebo $^{3}$, in patients with significant mitral regurgitation after a single dose ${ }^{6}$ or prolonged use ${ }^{12}$ of captopril, in adults with mitral regurgitation secondary to mitral valvular prolapse receiving ramipril ${ }^{9}$, and in healthy individuals after digoxin administration ${ }^{5}$.

Left ventricular end-systolic diameter decreased significantly in the phases in which digoxin and enalapril were administered, with no variation in the placebo phase (D).

Both the shortening and ejection fractions, as well as mean $\mathrm{dP} / \mathrm{dt}$, increased in the phases with drug administration, indicating an improvement in the parameters of ventricular function, a totally different behavior from that observed with placebo administration. Because preload remained unaltered, we believe that this was due to an increase in contractility with the use of digoxin and to a probable reduction in afterload with the use of enalapril. This may somehow be confirmed by the reduction in left ventricular wall stress observed in the groups receiving medication.

The forward systolic volume ejected from the left ventricle per heartbeat is another parameter indicative of left ventricular systolic function. Considering that this is the result of the difference between the diastolic and systolic ventricular volumes for each level of contractility, it has a direct correlation with preload and an inverse correlation with afterload. In normal situations, this volume is totally ejected in the aorta and constitutes the forward stroke volume.
In mitral regurgitation, a great part of the stroke volume flows back to the left atrium, and the forward stroke volume has an inverse relation with the mitral regurgitation volume. Considering that approximately half of the mitral regurgitation occurs prior to the aortic valve opening ${ }^{25}$, both the left ventricular end-systolic volume and the forward stroke volume are decreased in mitral regurgitation. In the present study, an increase in stroke volume was observed in the phases with drug administration, and a mild reduction was observed in the placebo phase; however, only the phase with digoxin showed a statistically significant increase. The mitral regurgitant fraction was also reduced in the phases with drug administration, and this reduction was significant only in the phase with digoxin.

Although it was previously proposed that the size of the regurgitant orifice diminished in situations with increased ventricular contractility or reduced intraventricular volume ${ }^{26,27}$, or both, this theory could not explain our results, because the velocity of the jet and not the regurgitation volume was the factor determining the size of the regurgitant area in color flow mapping ${ }^{28}$. Based on this, the mechanism of the difference observed between digoxin and enalapril could be explained by the capacity of the former to reduce the systolic preejection period ${ }^{29,30}$. Knowing that, in the presence of mitral regurgitation, the left ventricular forward stroke volume is inversely correlated with the mitral regurgitation volume, and considering that regurgitation occurs mainly in the systolic preejection phase ${ }^{25}$, a reduction in this period with digoxin may play an important role in regurgitation reduction, because it reduces the time in which regurgitation is more intense. Later on, with the aortic valve opening and a reduction in left ventricular systolic diameter, a reduction in the regurgitant orifice and an increase in the regurgitation velocity occur. At that moment, however, a great part of the intraventricular volume is also ejected into the aorta, diminishing the regurgitation volume, and, therefore, the velocity of the regurgitant jet. Considering that no significant variation in heart rate was observed, the reduction in the preejection period should be followed by an increase in the systolic ejection period. This mechanism could explain both the reduction in the valvular regurgitation and the increase in the stroke volume in patients with mitral regurgitation and preserved ventricular function with the use of digoxin.

The reduction in mitral regurgitation with the use of vasodilators was previously cited in patients with cardiomyopathy after receiving captopril for 8 to 12 weeks $^{3}$, and also in adults with significant mitral regurgitation receiving quinapril ${ }^{7,13}, \operatorname{losartan}^{8}$, and ramipril ${ }^{9}$. We believe that the mild variations here observed could achieve statistical significance in larger population samples.

Because previous studies do not exist indicating that the systolic preejection period may be altered by enalapril, unlike that which occurs with digoxin, the reduction in the regurgitation volume with enalapril should occur mainly in the systolic ejection period, when the reduction in afterload may favor a mild increase in left ventricular stroke volume with a reduction in regurgitation. These favorable effects, 
however, may be attenuated by the significant regurgitation of the preejection phase. Based on this, both the mitral regurgitation velocity, which determines the regurgitant jet area, and the stroke volume could be little altered.

The cardiopulmonary exercise test may help to characterize the functional class of the patients with mitral regurgitation. Of the 2 patients classified as functional class II on clinical evaluation who underwent the test, 1 had $\mathrm{VO}_{2}$ consumption levels compatible with functional class I and the other had them compatible with functional class III on the test performed after the use of placebo. This small number of patients does not allow conclusions about the mechanism involved in this difference between the clinical evaluation and that resulting from the cardiopulmonary exercise test. The last patient, however, had a worse left ventricular performance measured on echocardiography as compared with those of the other patients.

In this study, we observed an improvement in the parameters studied with the use of digoxin and enalapril. Al- though digoxin proved to be superior in some results, both were considered effective for this purpose, and the combination of the drugs showed no additional effect.

New studies should be carried out to elucidate whether the improvement in the parameters of ventricular function have beneficial effects on the long-term evolution of these patients, mainly considering the survival or evolution to surgical treatment, or both. As previously cited, patients with chronic mitral regurgitation may have an irreversible silent myocardial dysfunction ${ }^{31}$. Based on this, we currently do not know whether the treatment with digoxin or enalapril, or both, may beneficially delay the appearance of that dysfunction or mask its beginning or its evolution, or both, becoming, in this case, deleterious to the patient's evolution.

\section{Acknowledgements}

We thank CAPES (Coordenação de Aperfeiçoamento de Pessoal de Nível Superior) for their financial support.

\section{Referências}

1. Organização Panamericana de la Salud. Prevención de la Fiebre Reumática. Boletin Epidemiológico, OPS, 1980; 1: 1-4.

2. Ritchie JL, Cheitlin MD, Gardner TJ, et al. ACC/AHA guidelines for the management of patients with valvular heart disease: a report of the American College of Cardiology/American Heart Association task force on practice guidelines (committee on management of patients with valvular heart disease). J Am Coll Cardiol 1998; 32: 1486-588.

3. Seneviratne B, Moore GA, West PD. Effect of captopril on functional mitral regurgitation in dilated heart failure: a randomized double blind placebo controlled trial. Br Heart J 1994; 72: 63-8.

4. Seguchi M, Nakazawa M, Momma K. Effect of enalapril on infants and children with congestive heart failure. Cardiol Young 1992; 2: 14-9.

5. Crawford MH, Karliner JS, O'Rourke RA. Favorable effects of oral maintenance digoxin therapy on left ventricular performance ian normal subjects: echocardiographic study. Am J Cardiol 1976; 38: 843-7.

6. Wisenbaugh T, Essop R, Röthlisberger C, Sareli P. Effects of a single oral dose of captopril on left ventricular performance in severe mitral regurgitation. Am J Cardiol 1992; 69: 348-53.

7. Schön H-R, Schröter G, Blömer H, Schömig A. Beneficial effects of a single dose of quinapril on left ventricular performance in chronic mitral regurgitation. Am J Cardiol 1994; 73: 785-91

8. Dujardin KS, Enriquez-Sarano M, Bailey KR, Seward JB, Tajik J. Effect of losartan on degree of mitral regurgitation quantified by echocardiography. Am J Cardiol 2001; 87: 570-6.

9. HØst U, Kelbaek H, Hidelbrant P, Skagen K, Aldershvile J. Effect of ramipril on mitral regurgitation secondary to mitral valve prolapse. Am J Cardiol 1997; 80: 655-7.

10. Marcotte F, Honos GN, Walling AD, et al. Effect of angiotensin-converting enzyme inhibitor therapy in mitral regurgitation with normal left ventricular function. Can J Cardiol 1997; 13: 780-1.

11. Schön HR, Schömig A. Long-term treatment with quinapril in chronic aortic and mitral insufficiency. Dtsch Med Wochenschr 1995; 120: 429-35.

12. Wisenbaugh T, Sinovich V, Dullabh A, Sareli P. Six month pilot study of captopril for mildly symptomatic, severe isolated mitral and isolated aortic regurgitation. J Heart Valve Dis 1994; 3: 197-204.

13. Schön H-R, Schröter G, Barthel P, Schömig A. Quinapril therapy in patients with chronic mitral regurgitation. J Heart Valve Dis 1994; 3: 303-12.

14. Sahn DJ, DeMaria A, Kisslo J, Weyman A. The committee on M-mode standardization of the American Society of Echocardiography. Recommendations regarding quantitation in M-mode echocardiography: results of a survey of echocardiographic measurements. Circulation 1978; 58: 1072-83.

15. Teichholz LE, Kreulen T, Herman MV, Gorlin R. Problems in echocardiographic volume determinations: echocardiographic - angiographic correlations in the presence or absence of asynergy. Am J Cardiol 1976; 37: 7-11.

16. Williams GA, Labovitz AJ. Doppler estimation of cardiac output: principles and pitfalls. Echocardiography 1987; 4: 355-74.

17. Helmcke F, Nanda NC, Hsiung MC, et al. Color Doppler assessment of mitral regurgitation with orthogonal planes. Circulation 1987; 75: 175-83.

18. Quinones MA, Pickering E, Alexander JK. Percentage of shortening of the echocardiographic left ventricular dimension: its use in determining ejection fraction and stroke volume. Chest 1978; 74: 59-65.

19. Feigenbaum H. Echocardiography. $4^{\text {th }}$ ed., Philadelphia: Lea \& Febiger, 1986.

20. Quinones MA, Mokotoff DM, Nouri S, Winters WL, Miller RR. Noninvasive quantification of left ventricular wall stress: validation of method and application to assessment of chronic pressure overload. Am J Cardiol 1980; 45: 782-90.

21. Grossman W, Jones D, McLaurin LP. Wall stress and patterns of hypertrophy in the human left ventricle. J Clin Invest 1975; 56: 56-64.

22. Bargiggia GS, Bertucci C, Recusani F, et al. A new method for estimating left ventricular dP/dt by continuous wave Doppler - echocardiography: validation studies at cardiac catheterization. Circulation 1989; 80: 1287-92.

23. Henry WL, Gardin JM, Ware JH. Echocardiographic measurements in normal subjects from infancy to old age. Circulation 1980; 62: 1054-61.

24. Consensus study trial group. Effect of enalapril on mortality in severe congestive heart failure. Results of the CONSENSUS trial (Cooperative North Scandinavian Enalapril Survival Study). N Engl J Med 1987; 316: 1429-35.

25. Eckberg DL, Gault JH, Bouchard RL, Karliner JS, Ross J Jr. Mechanics of left ventricular contraction in chronic severe mitral regurgitation. Circulation 1973; 47 : 1252-9.

26. Yoran C, Yellin EL, Becker RM, Gabbay S, Frater RWM, Sonnenblick E. Dynamic aspects of acute mitral regurgitation: effects of ventricular volume, pressure and contractility on the effective regurgitant orifice area. Circulation 1979; 69: 170-6.

27. Borgenhagem DM, Serur JR, Gorlin R, Adams D, Sonnenblick EH. The effects of left ventricular load and contractility on mitral regurgitant orifice size and flow in the dog. Circulation 1977; 56: 106-13.

28. Losordo DW, Pastore JO, Coletta D, Kenny D, Isner JM. Limitations of color flow Doppler imaging in the quantification of valvular regurgitation: velocity of regurgitant jet, rather than volume, determines size of color Doppler image. Am Heart J 1993; 126: 168-76.

29. Taggart AJ, Johnston GD, McDevitt DG. Digoxin withdrawal after cardiac failure in patients with sinus rhythm. J Cardiovasc Pharmacol 1982; 5: 229-34.

30. Berman WJr, Yabek SM, Dillon T, Niland C, Corlew S, Christensen D. Effects of digoxin in infants with a congested circulatory state due to a ventricular septal defect. N Engl J Med 1983; 308: 363-6.

31. Ross Jr. J. Left ventricular function and the timing of surgical treatment in valvular heart disease. Ann Intern Med 1981; 94: 498-504. 